\title{
The Wandering Maps in the City of Bhubaneshwar, India.
}

\author{
Nibedita Mishra \\ Kamla Raheja Vidyanidhi \\ Institute for Architecture, JVPD, Mumbai, India \\ nibedita.mishra06@gmail.com
}

\begin{abstract}
In everyday life, walking is either considered as an exercise or as a necessity for conveyance. However, 'the walk' can create a complete new experience of the city - as Calvino describes in Invisible Cities. Walking produces space - the pedestrian city as contrasted with the city experienced in other ways. This paper seeks to describe the relationship of walking/wandering in the planned city of what Koenigsberger had imagined in Bhubaneswar in contrast to what the city now offers to a regular pedestrian.

The paper will discuss walking in the city of Bhubaneswar, planned by Koenigsberger, the first post-independence capital city, in the state of Orissa. The low-scaled neighbourhood planned city was to accommodate the requirements of modern life. Out of the eleven principles that the planner believed and integrated in the plans of Bhubaneswar, one of the main concepts was to bind the city within convenient walking distances. Bhubaneswar has recently been the first in the list to be selected under the Smart City proposal in India. The method includes analysis of walking through three parameters; the street, the public square and the alternative routes within the core city. The study is a documentation for further research in drawing cartographic and mind maps for documentation of further research in the rapidly growing city to uncover its layers of growth.
\end{abstract}

Keywords: Modernism, Post independent India, City, Bhubaneswar, Koenigsberger, Planning, Walking, Mapping.

\section{Introduction}

"Cities have the capability of providing something for everybody, only because, and only when, they are created by everybody."

Jane Jacobs, 1992: The Death and Life of Great American Cities.

With innovation at its core and old ideas and thought processes getting outdated over a period, Modernism came into existence in the early $20^{\text {th }}$ century. While India was still struggling to wake up to freedom 'at the stroke of the midnight hour' a part of 
the world had transcended from traditional forms of architecture, literature and philosophy to a more 'progressive' and self-conscious society. The modernist movement was at its peak in India when Nehru became India's first Prime Minister. This was the period when Lutyens' Delhi was already established to show India's glory and had become the identity as a powerful capital. This paved the way for many more such planned Indian cities.

Buildings of important twentieth century Capital cities in India had introduced different design philosophies, ideologies and concepts by the planners who were foreign to the Indian context. The approaches adopted by these architects in the capital city establishments were different, adhering to the relation of planning to the contexts of history, culture and people of the city. All these designers blended their theories and design principles with Indian typology. They faced challenges for designing within the Indian context at the time of independence and were given the task of building loud and monumental urban forms, which would represent India's proud existence in the age of modernism.

In the prevailing mood of post-independence India, the German-Indian planner Otto Koenigsberger created a people's participatory plan for the healthy growth and sustainability of the city of Bhubaneswar. He conceived a new Bhubaneswar along secular lines. In the context of political autonomy and commercial relationships, he designed a brave new realm in architecture that would accommodate aspirations and requisites for a modern life.

The paper focuses on the philosophy of Otto Koenigsberger's Bhubaneswar planning methodology that has enabled walkability. The objectives are to map out few existing routes in the city and the paper argues for the incorporation of the act of walking in planning through personal experiences. The act of walking also gives rise many a times to situations to explore or discover the hidden city. Sometimes walks are about the self and the city, and sometimes it is also about the collective. Many such collective walks govern or characterise a place depending on the pretexts of cultural and historical relevance. For example, the collective procession walks, carnival parades or may be the heritage walks in groups to bring out many perspectives and stories relevant to the city. There is also this idea of discovering and relating self with the neighbourhood through walking. The concept of the neighbourhood units are about being reachable within walking limits, but there are always short-cut routes and personal routes of conveying through the alleys and other roadways. Such walking in the city gives a person the feeling of belonging and make him/her aware of the surrounding with great responsibility. It opens out the self being a wanderer, cartographer or sometimes just building up on the idea of self being the lens, the kind of outlook Michael Sorkin describes in his book, 'Twenty Minutes in Manhattan' or Simon Sadler in the book 'The Situationist City'. The situationists imagined "the naked city" through the lens of the urban environment as it then existed. The paper is an attempt to rethink the act of wandering/walking as a method of mapping the city as a memory or personal experience.

To take these narratives and concepts ahead, the paper will elaborate on the different aspects of planning of the streets, squares and the alternative routes to talk 
about Bhubaneswar and Koenigsberger's vision in detail, and to describe how the city is produced through walking. Bhubaneswar was planned primarily on the theory pedestrianisation, to create a 'walkable' city. Thus, this paper aims to unravel the contrast of the city produced by the planner and the one produced by walking, from the perspective of the pedestrians, enabling consciousness towards the experience of wandering.

\section{City Building as a Prototype Model}

India, in search of an identity, appointed many eminent architects/planners from the West to build extravagant capitals. But each appointed Architect/Planner had his/her own ideology to work upon the given context. While Edwin Lutyen's Delhi was already built as a monumental capital, Koenigsberger was more grounded in his planning principles. Otto Koenigsberger planned many other company towns before he was appointed as the chief planner of Orissa. Albert Mayer and Matthew Nowicki, around the same time initiated the planning of Chandigarh adapting to the prevailing concept of modernisation and development within the context of Indian spatial planning, before Corbusier built it as a bold capital for Punjab after partition. On the contrary, Patrick Geddes researched and wrote extensively about new town planning methods in the Indian context and touched upon as many as eighteen Indian cities. Koenigsberger and Geddes both believed in John Ruskin's approach of examining the relationship of social processes and spatial forms. They believed that, by changing the spatial form, it is possible to transform social structure as well. Bhubaneswar values the act of preservation of human life and energy, rather than superficial beautification. The city also incorporates the action planning for future growth, which was nearly similar to Geddes ideas of an orderly development plan carried out in stages. All planners who came and worked in India during pre-and post-independence times employed the idea of city building as their ultimate goal, prioritising people's preferences and cultural requirements. While these ideologies are still referred to in current planning principles, walking or wandering as an act is dissolved under various different units of either 'Transit Oriented Development' or other 'Transport Planning' departments, mostly under a bigger scale of intervention for study and analysis. While all of them do look at planning of streets critically in an urban scenario, there is a gap in incorporation of understanding the phenomenology of wandering in the 'urban' context. The smart city planning arcs around large scale planning methods and high technology, completely ignore the basic pleasure of wandering in and around a city. The question arises whether the aspect of walking/ wandering could be as important as the other analytical aspects of street / mobility planning principle in an urban planning scale.

The street system within these planning methods were integral and designed to facilitate circulation within neighbourhood units and discourage its use by thorough traffic $^{1}$. Similarly, Jane Jacobs, who critiques neighbourhood planning and modern city building, explains:

\footnotetext{
${ }^{1}$ Perry Clarence, The Neighbourhood Unit, 1929, p110.
} 
"[a] city street equipped to handle strangers, and to make a safety asset, in itself, as the streets of successful city neighbourhoods always do, must have three main qualities: First, there must be a clear demarcation between what is public space and what is private space. Public and private spaces cannot ooze into each other as they do typically in suburban settings or in projects. Second, there must be eyes upon the street, eyes belonging to those we might call the natural proprietors of the street. The buildings on a street equipped to handle strangers and to ensure the safety of both residents and strangers, must be oriented to the street i.e., they cannot turn their backs or blank sides on it and leave it blind. And third, the sidewalk must have users on it, fairly continuously, both to add the number of effective eyes on the street and to induce the people in buildings along the street to watch the sidewalks in sufficient numbers. Nobody enjoys sitting on a stoop or looking out a window at an empty street. Almost nobody does such a thing. Large number of people entertain themselves, on and off, by watching street activity"

(Jacobs 1992: 35)

Interestingly, these ideas can be found in the overall planning objectives of Bhubaneswar. It also provides a sense to individual and community which blends with the diversity of the place; socially, culturally and climatically. I will describe in what follows how the city has transformed, and has integrated people, place and Nature. The study focusses on the aspect of wandering/walking as a celebration of the commonness in everyday life. Streets, I argue, are an essential component of the environment and community within which people meet and slowly bond, and are socialised. I will describe three prototypes of streets to explain how they affect cultural relationships within the city. The first is the street as a way of commute - where streets are designed for an efficient city/public transport. The second is the street as a site of recreation, in its use as a square, as public space and social interaction. The third is the street as an occasion for celebration, where streets provide the infrastructure for collective occasions and festivities.

\section{The Street Story: Street as Commute.}

Koenigsberger's approach to the street as commute is analysed further through three parameters: (1). Planning streets to keep the safety and lively factors activated within the neighbourhood units. (2). Understanding the role of "traffic" within the planned city. (3). Clearly defining the seven different types of roads for seven different groups of users and for seven different functions.

The most used and busy street of the city is the Rajpath - crossing the main spine of the capital city known as the Sachivalaya path and goes all the way till Janpath. The stretch covers two sectoral blocks and many interesting aspects of walking along these paths. The Rajpath starts from the Governor house, which is placed at the highest contour site, gives a view of the street as the boulevard, with the existing huge trees on both edges. The walk under the natural ecology, thus impacts a lot for people to 
commute through its playful light and shadow walking tracks of the city. Natural edges are for public, which opens out as the green/open space, to serve the people to access for recreation. This street meets the Sachivalaya path which houses the secretariat and various other government buildings. The lane takes 10 minutes as planned to reach from one chowk to the other, passing by the huge green setbacks, open spaces, small shrines, and many food vendors, encouraging people to come out and walk. Travelling within and around the Koenigsberger's planned city is made easier through different hierarchy of tracks within a road, which still prevails. His concept was to keep the city within walking limits and thereby save energy and resources. Inspired by the roads of historical towns, which were multi-purpose roads, Koenigsberger used the same idea in his planning in Bhubaneswar. They served a large variety of users ranging from pedestrians, animals, and cyclists to large trucks, buses and motor cars for a large variety of purposes ranging from simple access to residences to fast movements from one point of the settlement to the other. The functional analysis of these roads was done well to serve localities and design them with special regard to their prior functions. In some instances, there has been a limit to the use of certain roads to restricted groups of users with the objective to create what may be termed as 'specialised' type of roads. And these special roads which were allotted according to the use are implemented in the planning of Bhubaneswar and are differentiated strictly between 7 different types of roads for 7 different groups of users and for 7 different functions. The easy connectivity within the residential sectors from recreational to institutional parts was all within 10 minutes reachable distance, a strikingly well bound form that emphasised more on the collective, with safety being a guiding factor for the city. To elaborate on his segregation of road networks, walking was always the dominating idea behind the type of paths. The report highlights the following features that are relevant to walkability:

(i) Foot-Paths: These roads were meant to be aligned independently from other roads with the objective of providing the shortest possible routes for pedestrians. Footpaths were planned to be laid out mainly within the neighborhood units to guarantee easy access from houses to schools, shopping centers and to the bus stops on the main roads.

(ii) Parkways: These are footpaths in recreational areas designed to include the informal, generally used for leisurely walking, as an experience as opposed to an objective driven trip.

(iii) Cycle-paths: These are similar to footpaths, which were planned to be independent from other roads though they may at times, run parallel with them. They were thought to provide short connections from residences to secondary high schools, shopping centers, offices and factories, but with special care to avoid blind corners and dangerous inter-sections with other traffic.

(iv) Minor housing streets: Housing streets were planned to give access to houses. By their alignment, they discouraged the passage of vehicles in a children-friendly neighbourhood. For this reason, Koenigsberger believed in cul-de-sacs to be well suited for housing streets. Children were allowed to roam about on such streets, which were thought to be rarely used by vehicular traffic. The characters of Minor Housing Streets 
were envisioned to be dominated entirely by the need to give access to residential quarters.

(v) Major Housing Streets: These were intended to collect the local traffic of several minor housing streets. Major Housing Streets would require additional width to cater to the small amount of traffic collected from the adjoining minor streets, but they were still local in character although traffic was supposed to be avoided carefully.

(vi) Main Roads: These were the primary roads intended for traffic. Their functions were to collect the traffic from housing streets and connect it to important centers and to the main artery. It was clear from this definition that houses had no place along main roads except in exceptional cases. The two functions of giving access to houses and of catering to fast traffic are almost incompatible. During the 1940s when Koenigsberger was awarded the plan, more than 80 percent of the accidents and traffic-driven hazards in towns were due to the fact that planners and traffic Engineers had not attempted this incompatibility and had tried to strike compromises.

The main roads as traffic routes are not particularly wide but designed for a smooth flow of traffic. This study of road statistic shows that hold up and congestion are not merely functions of the number of road users but are due to the fact that traffic in traditional city streets is constantly held up by intersections and outlets from buildings and by parking and stopping.

(vii) Main Arteries - the main artery collects a considerable amount of traffic, this road has even further divisions of functions in the shape of separate lanes not only for the two directions of traffic, but also for road users of different speed. As Koenigsberger had studied the Indian roads and the way they were used, he conveyed that there must be separate tracks for pedestrians, cyclists, bullock carts and slow-moving motor traffic and for mechanised mass transport. He states that though this system of specialised roads may sound expensive, detailed estimates confirm that specialisation of roads brings considerable savings both in capital outlay and in running expenditure. Under the old system, the cost (per mile) of all roads in towns was roughly the same, because no road could be built below a certain minimum standard.

The above seven types of road networks which Koenigsberger had hand-written to be planned for the new capital, Bhubaneswar, is the key to develop an inclusive pedestrian plan for the city. The purpose and future use of any particular road was not predicted with any certainty, and was kept fairly wide and well-built to be prepared for all eventualities. Although the original plan followed the system, the current TOD (Transit Oriented Development) for the newer smart city planning failed to understand and implement these principles. Koenigsberger, could envision the city's requirement 70 years ago and accommodated the people and the ordinary of the city. He planned more than 80 percent of all roads to be housing streets. Only a small fraction was traffic streets, out of which only a few miles formed the main artery. Housing streets were inexpensively built because they were used only by the owners of the adjoining houses, and by people who came to see them as friends or on business. These housing streets are well maintained as a part of their daily rituals where one could often see the different 
rangoli patterns (chitta) on the floor at the entrances. Traffic roads adjoining these streets are not particularly expensive and wide, as the smooth flow of traffic is guaranteed by avoiding intersection and disturbances rather than by an increase in the width of the paved areas.

The equipped road networks, blocking the neighbourhood from heavy vehicular entry, allows people to adapt to walk, cycle and run which also creates an association within the communities around. Koenigsberger claimed that the savings in housing and ordinary traffic streets would permit to spend more on the main arteries, which can be developed in accordance with the latest and highest demands of the science of road making. Owing to their short length, they will add very little to the overall cost. ${ }^{2}$

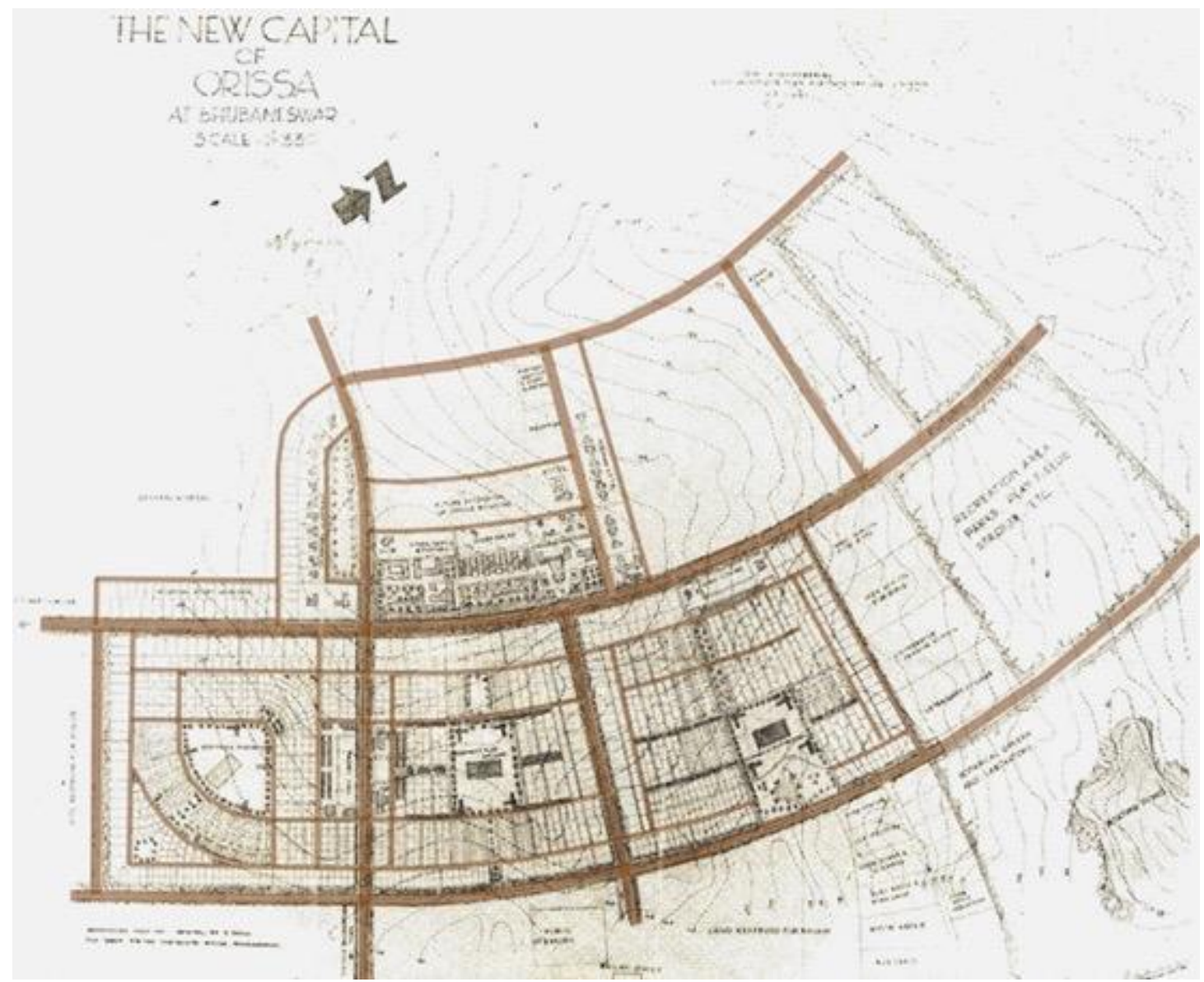

Fig. 1: Different types of roads for different groups of users and for different functions.

Source: Otto Koenigsberger's map annotated by author

The existing roundabouts, traffic lights and traffic police men are hardly a necessity in the well-designed modern road system based on hierarchies in road functions, which was a futuristic thought by Koenigsberger. The maintenance of roads was easier

\footnotetext{
2 Based on the writings of Koenigsberger, Otto H. (1948) MASTER PALN OF THE NEW CAPITAL
} CITY OF ORISSA AT BHUBANESWAR. Submitted to the Government of Orissa, p14. 
because their use was pre-determined and taken into consideration from the very beginning when deciding the depth of foundations and the necessary amount of consolidation covering and waterproofing. To avoid misunderstanding, it was stressed that the foregoing observations referred entirely to those portions of the roadways, which are required to carry actual traffic. The overall widths of the land reserved for roads and streets were not determined by traffic alone, but by the requirements of space for storm water drainage and services (overhead electric lines, telephone, water etc.) and, above all, need of sufficient light and air to the adjoining houses. The overall width of land allotment for road purposes was therefore dependent on the height of houses on both sides. The predominantly low-rise fabric of the city, with regular open spaces, apart from the residents and the parking space, gives no room for negative space and keeps each neighbourhood actively equipped with play, recreation and gathering space.

Another important consideration in the land allotment for road purposes was the space required for avenue trees along the housing sectors. Mostly, all roads (except cycle paths and footpaths) in the city are planned with avenue trees as an essential and necessary provision; both in the land allotment scheme and in the estimate sector. The establishment of a tree nursery is essential to simultaneously form roads and building houses. Thus, the walkways provide shaded walks through space and enhances people to walk along the pathways, enjoying such pockets within a neighbourhood. It was due to the requirements other than traffic that the allotment of land even for the smallest housing street at Bhubaneswar was fixed at a minimum of 30 feet. Only about 9 feet out of this 30 actually carries traffic. The remainder is used for storm water drainage, avenue trees and services and to keep the two rows of houses sufficiently apart from each other to guarantee a fair share of the cool breeze to every house. ${ }^{3}$

The system proposed for Odisha's capital consists of one main line to which few branches are added later. The idea eliminates the need for complicated circular routes, crossings and by-passes. The ideas of the planner allow for major future development in the city and opens up scope for incorporating newer transport planning within the urban fabric, irrespective of whether the town would have electrical trains, electric tram lines, electric trolley buses, petrol, diesel oil or producer gas driven vehicles. ${ }^{4}$

This connecting link was supplemented by many other unifying elements, most important element being the central group of public buildings. The word "central"e does not mean that this group necessarily lies in the centre of the city. It does not matter at which point of the main artery the public buildings are situated, as they are all connected with this artery. The public buildings are spread out evenly along the main road, which makes it more reachable within a walking trail. These monumental group of public buildings gathered around with pleasing built proportions, are an important integrating force for the life of the town, referencing with the old idea of the "Agora". The central group of buildings also include the popular representation in the

\footnotetext{
${ }^{3}$ Based on the writings of Koenigsberger, Otto H. (1948) MASTER PALN OF THE NEW CAPITAL CITY OF ORISSA AT BHUBANESWAR. Submitted to the Government of Orissa, p14.

${ }^{4}$ Ibid, p10.
} 
government: public libraries, museum, centres of social services, meeting places and assembly halls of all kinds.

An interesting comparison is drawn regarding the Central Secretariat buildings (Rajpath) in Delhi, which are alive at day-time but appear like a deserted mass of stone on holidays or in the evenings. The central group of public buildings at Bhubaneswar (Rajpath) is more than merely a 'Central Secretariat' and is constantly active and forms a lively focal point for all kinds of public life in the town. A centre of this kind gives the citizens of the capital a feeling of belonging together and of forming part of one great city, however different they may wish to develop the individual neighbourhood units in which they reside" (Mishra 2011). These public fora, on an urban scale, provides space in favour of the pedestrian, the cyclist, the free runner, and the explorer to walk, map and associate with the city.

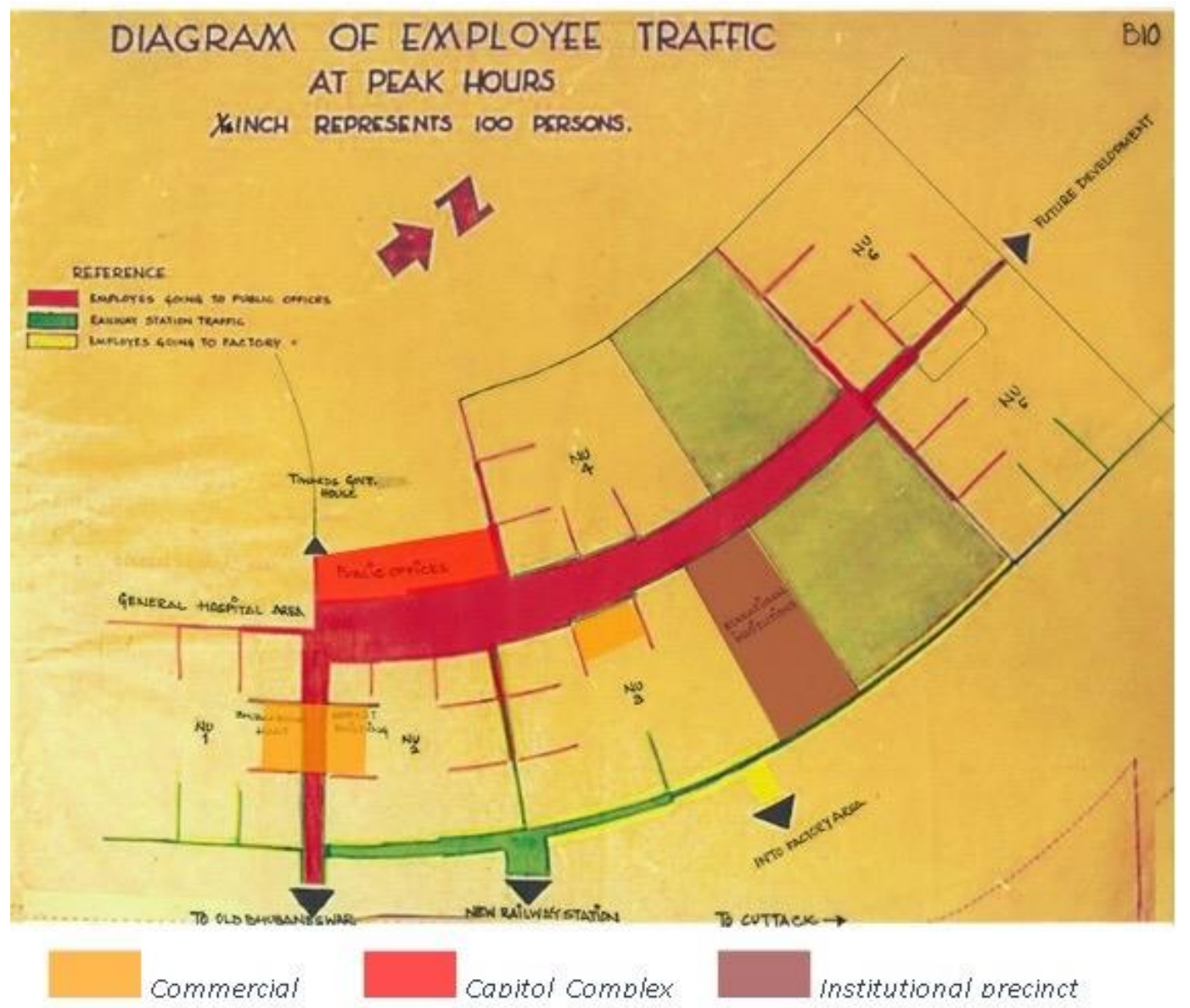

Fig 2: Diagram for traffic flow during peak hours.

Source: Otto Koenigsberger's map annotated by author

One walks to explore, to see and observe within the capacity of walking. Any city planning faces challenges to enable such acts of walking towards what makes a great city. Koenigsberger to some extent has been able to solve the basic issue in improving the fabric and experience of urban life through enabling basic awareness for the 
physical form of the neighbourhood. Creating these conditions requires attention to a broad range of criteria. There are various research studies undertaken, focusing on making a city attractive to pedestrians, which highlights on the idea that walks must be useful, safe, comfortable and interesting to attract people to walk. ${ }^{5}$ It thus allows the momentum to facilitate the act of walking. The planning of the core city overlapping the site on the grounds of heritage, history, climate and above all the ordinary people, produces many personalised walkable spaces. It gives room for everyone in the city to associate themselves with the built-up and celebrate in their daily life.

\section{The Square: Street as a site of Recreation}

Koenigsberger's introduction of street layouts that create urban plazas are analysed through: (1). The easy walkability or accessibility to a plaza or recreation space provided in every neighbourhood unit (2). Introduction of the urban plaza in the Indian context (3). Plazas primarily serving as markets.

The squares are the most exciting parts of the city, for recreation, meeting, relaxing leisure and an active space at all times of the day. As one walks, ahead of the A.G. square, within 5 minutes she/he reaches the central market building, and the shopping square. The square at Bhubaneswar is open plan with markets on both edges attached to a long semi open verandah space considering the hot and humid climate of the city. Architecturally, the elements from market building design are borrowed from temple architecture of the city. These include the overhang verandah for rain, trabeated style of the roofs of shopping blocks, horizontal tiers/bands on the facade of the buildings elevation and the clock tower at the center of the market building, smoothly evolves from the history of the temple profile to a contemporary market square.

The square prioritizes for pedestrians by blocking the vehicular access at the entry of the market through a large flight of steps to enter the space for recreation. There were many arguments when the square was being built, to make it into a market street instead of a market square. But I agree with what the planner believed, of that the connection of shopping activities with roads which was primarily intended for the movement of traffic, and converting a part of the stretch into a market street would have been a disjunction from what the planner envisioned for the city. Thus, differentiation in functions was desirable to guarantee convenient shopping and safety for users of all kinds. The plan for the Odisha capital provides, therefore, shopping squares but no shopping streets. ${ }^{6}$ The shopping squares are accessible from the main roads, but at the same time clearly separated from them, so that fast-traffic can move undisturbed and people can buy their provisions at leisure without danger of being run over. The idea of concentrating shops around shopping squares links up with the tradition of Indian bazaars. Indian Bazaars were never meant to be thoroughfares for fast moving traffic, but concentrated areas for undistributed trade. The concentration of shops facilitates

\footnotetext{
${ }^{5}$ Speck Jeff, Walkable City, 2012.

${ }^{6}$ Based on the writings of Koenigsberger, Otto H. (1948) MASTER PALN OF THE NEW CAPITAL CITY OF ORISSA AT BHUBANESWAR. Submitted to the Government of Orissa, p13.
} 
supervision and enforced healthy competition would not develop if shops were dispersed along traffic roads and housing streets.

Dispersed shops usually rely on attracting customers on the convenience of being near. They are, therefore, less efficient and offer services inferior to those shops which are concentrated in bazaars and shopping squares where they have to compete with large number of similar stores. This concept is reflected in Unit 1 market, Bhubaneswar, which is famously known as the Haat with all local and wide range of goods. Every neighbourhood has a market square attached to it, which is well-connected within the unit through lanes. However, the central and important ones are the Unit-I and Unit-II market complex, which are vivid and solid examples of the city's clean and beautifully worked out open public spaces.

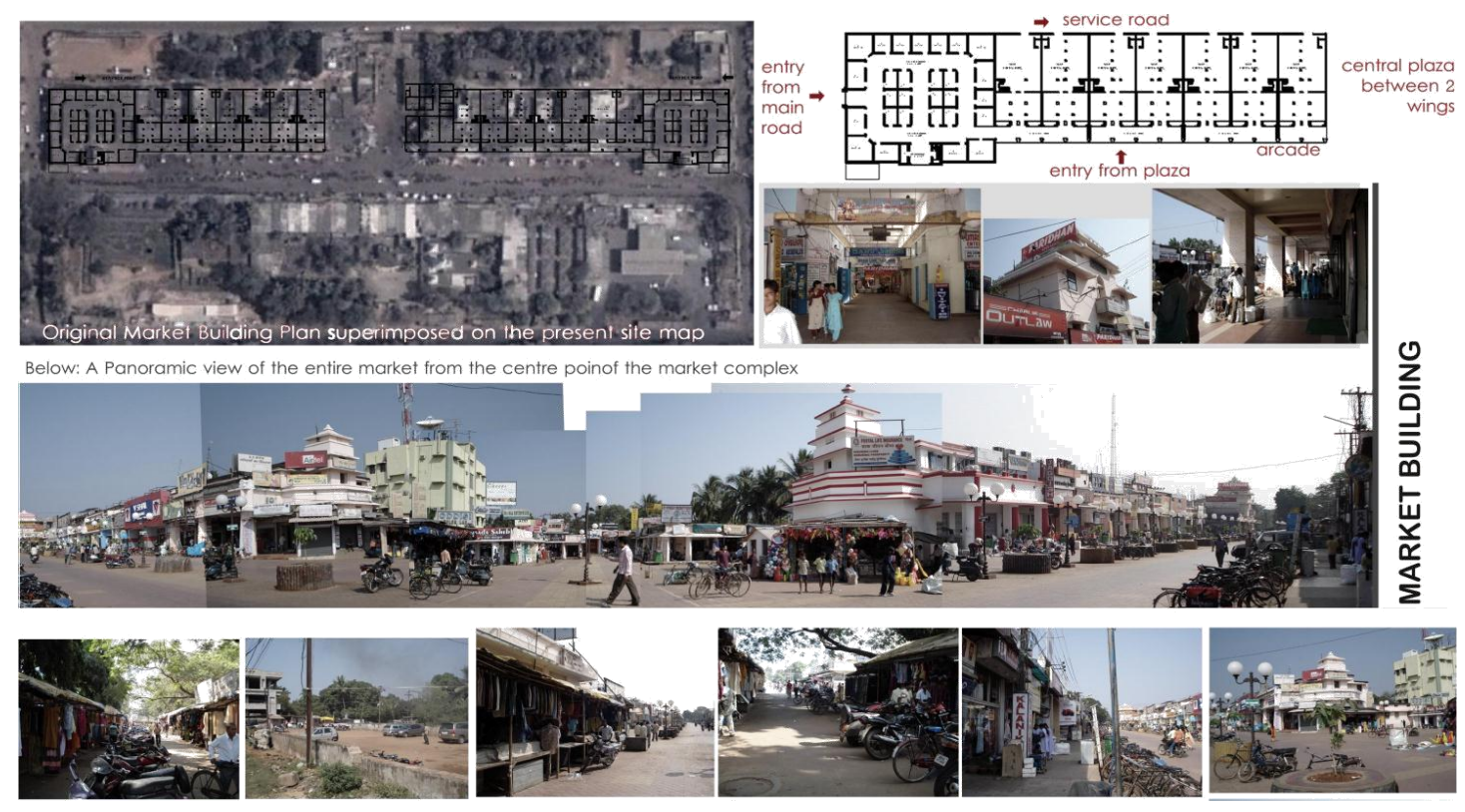

Fig 3: Market Building, Unit 1, Illustrations. Source: Author

The physical and social dynamics of public space plays the central role in the formation of public culture in Bhubaneswar. The city's streets, parks, squares, and other shared spaces are seen as symbols of collective well-being and prosperity. Expressions of achievement and aspiration by urban leaders are seen through the visionaries for the formation of civic culture, and significant spaces of political deliberation and antagonistic struggle. With multiple usage of public space and proliferation of the sites of political and cultural expression, it seems odd to expect public spaces to fulfil their traditional role as spaces of civic inculcation and political participation. But that was what Koenigsberger aimed at and today, though the city is still evolving as a smart city, the parts designed by the planner boasts of public spaces which seek high attention and are properly planned so as to nurture the needs of the people. Public spaces in Bhubaneswar were not designed as negative spaces, or leftover spaces from the dwellings. Rather, they were designed consciously, as an integral planning aspect of the 
city. These spaces that are planned out and designed by Koenigsberger appears to be specifically created as places for assembly, for the market, for the festivals and celebration and a variety of purposes much of which today's contemporary designs in Bhubaneswar lack.

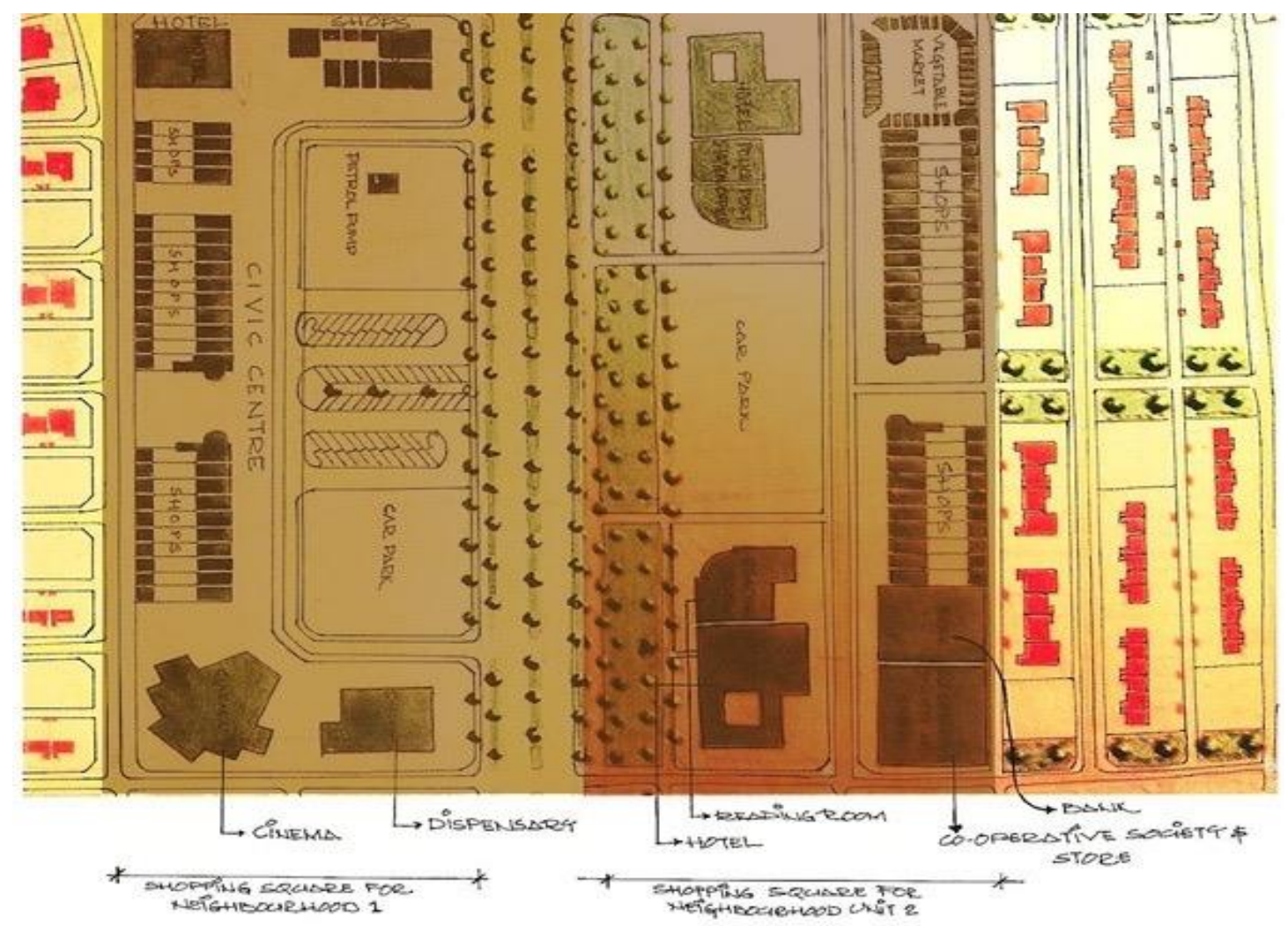

Fig 4: Market Building, Unit 1, Detailed Plan.

Source: Otto Koenigsberger's map annotated by author.

However, as an open space, the market-square serves much more than what it is intended to do, as it caters to purely pedestrian space within the city for all kinds and classes of people as another space for recreation, to enjoy the food, shopping, meeting and appreciating the local culture of city.

\section{The Alternative Routes: Street as an Occasion for Celebration}

Alternative walking routes are described here through (1). Facilitating walking within the city through the creation of mixed use, mixed income neighbourhoods (2). Short cut routes and pause points (3). Creating the infrastructure for festive occasions.

The paper has argued about the city's aspect of walkability, which was meant to remain as the predominant means of transport for all residences as near as possible to the centre of commercial or professional interest. However, with the ingress of cars, walking has taken a backseat and has become a passive act currently. The concept of sectoral planning has facilitated and evolved the act of walking with the citizens over years, 
which opens out provisions of amenities like schools, hospitals and markets within walking distances; concepts similar to those followed by any new towns formulated in times of modernism. These ideologies are forgotten in city governance today, restricting the choice to live at a walkable distance. However, the grid plan of the city provides an organised lifestyle for all groups who live in the core and periphery. They can thus engage in activities with the city. The citizens found it easier to integrate within the planned city as the peripheral city gave no scope for integration of the growth due to its rigid nature.

Transformations that have happened over time have bought variations according to time and theme. There were various factors that were important with regards to the context of planning new towns, which were carried forward by Koenigsberger as per his theories regarding tropical architecture. Most important of them would be the possibility of creating wandering ways across the city. The city opens out many short cut routes for pedestrians, pause points with sitting facilities, quiet reading corners, junctions for conversations, and areas for laughing clubs for senior citizens within the units. The evening leisure time is spent on allotted chowks of every neighbourhood junctions within various age groups. The chowks thus also act as recreation places for chatting, walking, eating and relaxation in a day-to-day life. Celebrating other collective occasions like various festivals, religious get togethers, gatherings for rally, and assembling for parade provide space for open talks. They become a part of livelihood within these streets of the city. The street of Bhubaneswar accommodates all these acts and events.

Bhubaneswar has ample scope for future expansion, because its grid planning is interconnected and compact providing scope for the accessibility from one corner to another, near enough to be reached on foot or bicycle. The city remains unified and democratic through his design. Neighbourhood units of the new towns in India form the best possible link with the type of community life are familiar within their villages. Each neighbourhood is a cross section of the population, taking good care to have all social and professional groups represented, roughly in its relative strength in the whole community. The village-like neighbourhood of the new towns makes it easier for citizens to understand their civic responsibilities than a large amorphous city. ${ }^{7}$ Koenigsberger understood the psyche of the people residing in the city, and planned with appropriate tropical traditions and habits of outdoor living in India, which provide important opportunities for inexpensive but effective solutions for new Indian cities.

Designing capitals is more than a flamboyant urban complex, wide roads and spacious green neighbourhoods. It is imbibing what our culture stands for. The home of the most ancient city builders does not need imported architects or planners to design and plan their city. The city needs city buildings, which also cater to the people who literally build them. The analysis of the architecture of Bhubaneswar well clarifies that Koenigsberger had used the design solutions, understanding and studying the tradition of Orissa. He proposed the city plan in a contemporary vocabulary taking clues from

\footnotetext{
${ }^{7}$ Koenigsbeger, Otto H. NEW TOWNS IN INDIA. Town Planning Review, vol. 23, no.2, July 1952. P 105.
} 
the local traditional architecture. Koenigsberger's city plan demands people to participate in making the city ecological. Thus, planning provided ample room for the people around to associate themselves with the city not just in a two-dimensional way but more of a personal association. The association has evolved and transformed over the years, keeping the narratives of the building of a capital alive for the generation of today as well.

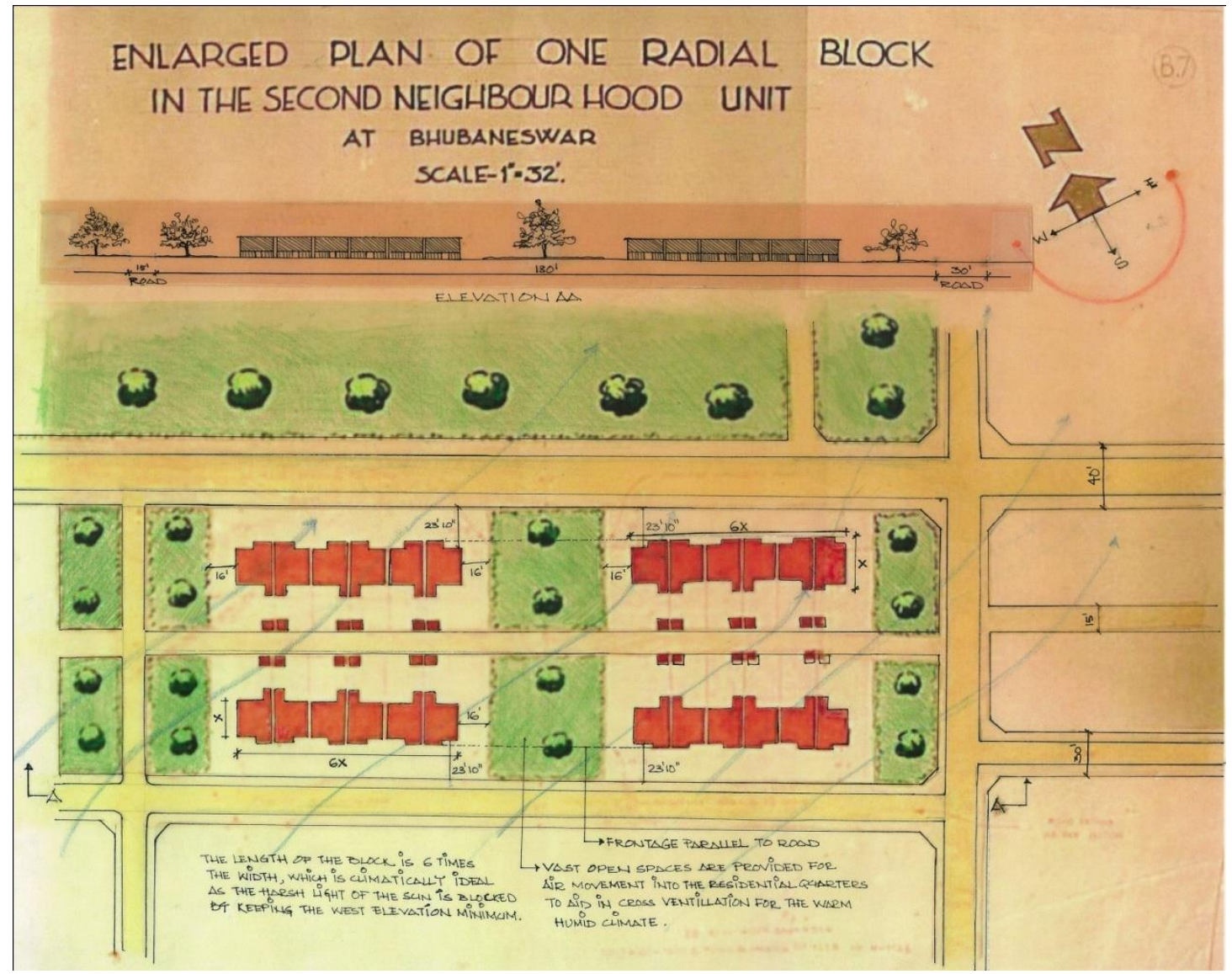

Fig 5: Detailed Residential Plan within the Neighbourhood.

Source: Otto Koenigsberger's map annotated by author.

The statistics show that Bhubaneswar being planned for pedestrians have only 40 percent population who choose to walk within the city, with or without compulsion. Hence, the question arises as to whether the act of walking has been encouraged through designing or planning principles in the city? Walkable city is a practical solution to a number of problems that affects both our daily lives as individuals and our economic, environmental, and cultural health as a society. So, the city should use the existing parameters to encourage bikes, enhancing transit, and making the city attractive to a broader range of people towards walking. Walking, a non-expensive mode of activity, also helps us to thrive economically. We can imagine walking being safe as well as a healthy option. The act also encourages city to be sustainable for the 
generations to come. Walkability is most useful as it contributes to urban vitality and most meaningful as an indicator of that vitality. ${ }^{8}$

\section{Conclusion}

Cities, highly contextual in nature, symbolize our dignity. Cities are collections of artefacts and have always set the backdrop for innovation and monumentality in architecture. Hence, it is crucial for cities to be well planned and inclusive. The need for an image of the city, and value associations with liveability, accessibility and safety/security become imperative. Harmony with tradition, pluralism and conservation of resource and skill aid to better functioning of the city, where there is a symbiotic relationship between place and citizens. In contemporary contexts, the smart city concept seems to overlook this aspect of complexity in the urban fabric, which has been an age-old act by many Indian cities before the intervention of planners acting as facilitators.

Otto Koenigsberger studied and mastered the understanding of the Indian context, welcoming the challenges and differences encountered while planning a city of such rich ancient heritage. His beliefs are looked up to because the plan had the potential to grow beyond the lines he had originally laid. Though parts of the city have remained faithful to the plan, it has grown rapidly over the last few decades (now proposed as smart city) and has made the planning progress unwieldy. Overlays of time have brought about lots of layering to the city. His ideologies are taken ahead and implemented in the city planning and growth, where Koenigsberger designed the city, keeping the aspect of uncovering the experience of walking open. He wanted the user to discover the possibility of new experiences that could be used as a lens to view the same. The planner anticipated the various possibilities and experiences of street use through the materiality, sensory properties and the overall atmosphere. The research could thus be taken further ahead to map these layers of growth through mind maps, collaborative experiential maps, and situationist maps etc. to document and establish the relationship of people's participation in the growth of the city, where all classes and ages of people can come together to share their experiences. The plug-in of these maps can make it relevant and contextual to time through research, that could be integrated in the process of academia and profession; as pure research (informative), descriptive, interpretive, critical, constructivism or even participatory, research of any form that can become a base information, informing for a better learning and practice in Architecture. Currently, there are various adaptations of new concepts to make cities more walkable through well-connected public amenities within a comfortable walking radius of neighbourhood, to ensure that the streets are active. Koenigsberger's Bhubaneswar, has scope to accommodate and implement all the above ideas and changes that makes it, if not now, prospect good streets within the city form.

Walking, wandering and exploring the city through understanding and valuing the pause points and intersections in cities, can be facilitated through urban design strategies. A place for conjunctions, driven by the fundamental human senses, the street

\footnotetext{
${ }^{8}$ Speck Jeff, Walkable City, 2012.
} 
and the act of walking enhances not only the systems of exchanges within a specified realm, but eventually transgresses into developing the ethos of observing and absorbing. Both are critical aspects for revitalising the mechanised Indian city of today, towards the production of 'places' for its citizens. However, in recent times, we have adopted a new attitude towards city development. It primarily undermines our future, ignoring the important and indispensable aspects in pursuit of improper urban inequities. The answer to most of these transit design problems are quite simple, like small adjustments, up gradation and improvements of the existing facilities, intelligent management, accountability and regulations. Koenigsberger's model has provisions for all of these; it is affordable, inclusive, efficient and timeless. Therefore, the infrastructure and institutions we build today for the sake of development must be a conscious decision of how we wish or imagine our tomorrow to be. In the era where everyone chases and wants everything 'smart' and 'high tech', we need to retrospect how much space do we have for these simple aspects of wandering, associating self with the site, context, city and history.

\section{References}

Calvino, Italo (1974), Invisible Cities, 1st edn., Great Britain: Secker \& Warburg Ltd.

Holston, James (1999), Cities and Citizenship - Spaces for insurgent citizens!, Duke University Press.

Jacob, Jane (1992), The Death and Life of Great American Cities, New York: Vintage Books, A Division of Random House, Inc.

Jacobs, Allan B. (1993), Great Streets, USA: MIT Press.

Kalia, Ravi (1994), Bhubaneswar From A Temple Town to a Capital City, Southern Illinois University. Koenigsberger, Otto H (1948), Master Plan Of the New Capital City of Orissa at Bhubaneswar, Submitted to the Government of Orissa.

Koenigsberger, Otto H (1952, July), New Towns In India, Town Planning Review, vol. 23, no.2.

Lang, Jon. Desai, Madhvi. Desai, Miki (1997), Architecture and Independence, the search for Identity India 1880 to 1980 . Oxford University Press.

Lawrence, J. Vale. Architecture (1992), Power and National Identity, New Haven, Conn., and London. Yale University Press.

Mehta, Jaimini (2011), Rethinking Modernity, towards post rational architecture. New Delhi: Niyogi Books.

Mishra, Nibedita (2011), Master's Thesis: Koenigsberger's Bhubaneswar, CEPT University. (unpublished)

Rossi, Aldo (1982), Architecture of the City, MIT Press.

Sadler, Simon (1999), The Situationist City, MIT Press.

Sorkin, Michael (2009), Twenty Minutes in Manhattan, 1st edn, London: Reaktion Books Ltd.

Speck Jeff (2012), Walkable City: How Downtown Can Save America, One Step at a Time, New York: Farrar, Straus and Giroux, North Point Press.

Vidyarthi Sanjeev (2015), One Idea, Many Plans: An American City Design Concept in Independent India, New York: Routledge.

Vox, Superblocks: How Barcelona is taking city streets back from cars, viewed 2017, https://www.facebook.com/ezraklein/videos/676725529181719/ 